\title{
Effect of the inclusion of quebracho tannins in a diet rich in linoleic acid on milk fatty acid composition in dairy ewes
}

\author{
P. G. Toral, G. Hervás, A. Belenguer, E. Bichi, and P. Frutos ${ }^{1}$ \\ Instituto de Ganadería de Montaña (CSIC-ULE), Finca Marzanas s/n, 24346 Grulleros, León, Spain
}

\section{ABSTRACT}

Despite controversy surrounding the ability of tannins to modulate the fatty acid (FA) profile of ruminantderived products, reports on this issue are still very limited for dairy sheep. This study was conducted to examine the effect of the inclusion of quebracho tannins in a diet rich in linoleic acid on ewe performance and milk FA composition. Thirty-six lactating ewes were distributed into 6 lots and allocated to 2 treatments (3 lots/treatment): control or quebracho. All sheep received a total mixed ration based on alfalfa hay and a concentrate (forage:concentrate ratio of 40:60) supplemented with $20 \mathrm{~g}$ of sunflower oil $/ \mathrm{kg}$ of dry matter plus 0 (control diet) or $20 \mathrm{~g}$ of an extract of quebracho tannins $/ \mathrm{kg}$ of dry matter (QUE diet). Milk production and composition were analyzed on d $0,3,6,9,12,15$, $18,21,24$, and 27 on treatments, and milk FA profile on d $0,3,6,12,18$, and 27 . On d 27, samples of rumen fluid were collected for $\mathrm{pH}$, and lactate, ammonia, and volatile FA concentration analysis. Feeding the QUE diet had no apparent effect on animal performance and hardly modified ruminal fermentation characteristics, except for a reduction in the molar proportions of minor volatile FA. Dietary tannins increased the milk concentration of several 18:1 and 18:2 isomers and decreased that of branched-chain FA. Some of these changes were relatively constant throughout the experiment (e.g., cis-12 18:1 and trans-9,cis-12 18:2), whereas others varied over time (e.g., trans-10 18:1, which increased gradually with the QUE diet). Significant differences between treatments in trans-11 18:1 and cis-9,trans-11 conjugated linoleic acid were only observed on d 3 . Overall, addition of quebracho tannins to a diet rich in linoleic acid did not prove useful to beneficially modify milk FA composition, especially over the long term.

Key words: biohydrogenation, condensed tannin, sheep, trans fatty acid

Received April 14, 2012

Accepted October 13, 2012.

${ }^{1}$ Corresponding author: p.frutos@csic.es
INTRODUCTION

Based on their potential benefits to consumer health, large interest exists in enhancing levels of some healthpromoting FA in ruminant-derived products (Chilliard et al., 2007; Vasta and Luciano, 2011). Increased levels may be achieved through nutritional strategies inhibiting ruminal biohydrogenation $(\mathbf{B H})$ of dietary long-chain PUFA or promoting the accumulation in the rumen of conjugated linoleic acid (CLA) precursors, such as trans-11 18:1 (vaccenic acid, VA; Lock and Bauman, 2004; Chilliard et al., 2007).

Some in vitro studies have suggested that tannins can exert these effects by impairing rumen microbial $\mathrm{BH}$ in general and the conversion of 18:1 to 18:0 in particular (Khiaosa-Ard et al., 2009; Vasta et al., 2009a; Buccioni et al., 2011). However, this has rarely been validated in vivo (Vasta et al., 2009b; Khiaosa-ard et al., 2011) and most experiments seem to point in a different direction (Kronberg et al., 2007; Benchaar and Chouinard, 2009; Cabiddu et al., 2009). In any case, reports on this issue are still limited and inconsistent.

In a recent study, Toral et al. (2011) examined the effect of the addition of hydrolysable and condensed tannins (namely, a proportional mixture of quebracho and chestnut tannin extracts; $10 \mathrm{~g} / \mathrm{kg}$ of DM) to a diet containing sunflower oil (as a source of linoleic acid to increase ruminal formation of VA; Honkanen et al., 2012). Tannin supplementation had no effect on animal performance and was not able to enhance milk VA and CLA enrichment above that achieved with the presence of sunflower oil in the diet (Hervás et al., 2008; Toral et al., 2010). Given the great diversity in the structural features and, consequently, in the reactivity of different tannins (Mueller-Harvey, 2006), the lack of effects was attributed to the type and amount in the diet, which encourages further research to investigate the potential of these phenolic compounds to favorably modify ruminal BH and milk fat composition. Therefore, this study was conducted to examine the effect of the addition of an extract of condensed tannins (quebracho), at a higher inclusion rate $(20 \mathrm{~g} / \mathrm{kg}$ of $\mathrm{DM})$, to a diet rich in linoleic acid, on lactating ewe performance and milk composition, with special focus on the FA profile. 


\section{MATERIALS AND METHODS}

\section{Animals, Experimental Diets, and Management}

Thirty-six Assaf ewes $(\mathrm{BW}=81.2 \pm 1.49 \mathrm{~kg} ; \mathrm{DIM}$ $=43 \pm 0.7)$ were housed in individual tiestalls and distributed according to milk production, BW, DIM, number of lactation, and voluntary feed intake, in 6 balanced lots of 6 animals each. Lots were then randomly assigned to 2 experimental treatments (3 lots/ treatment): control or supplemented with quebracho tannins (QUE).

Diets, prepared weekly, consisted of a TMR based on alfalfa hay (particle size $>4 \mathrm{~cm}$ ) and a concentrate (forage:concentrate ratio of 40:60), supplemented with $20 \mathrm{~g}$ of sunflower oil $/ \mathrm{kg}$ of DM plus 0 (control diet) or 20 (QUE diet) $\mathrm{g}$ of a commercial extract of quebracho tannins (TanicolMOX; Agrovin SA, Alcázar de San Juan, Spain; declared tannin content >900 g/ $\mathrm{kg}$ of DM). The ingredients and chemical composition of diets, which included molasses to reduce selection of dietary components, are given in Table 1. Before commencing the experiment, all animals received the control TMR during a 2-wk adaptation period. Clean water was always available and fresh diets were offered daily ad libitum at 0900 and $1900 \mathrm{~h}$.

Ewes were milked at approximately 0830 and 1830 $\mathrm{h}$ in a $1 \times 10$ stall milking parlor (DeLaval, Madrid,
Spain). The trial lasted for $4 \mathrm{wk}$, and was conducted in accordance with Spanish Royal Decree 1201/2005 for the protection of animals used for experimental purposes.

\section{Measurements and Sampling Procedures}

Diets. Samples of offered and refused diets were collected every $4 \mathrm{~d}$, stored at $-30^{\circ} \mathrm{C}$, and freeze dried.

Milk. Individual daily milk yield was recorded on d $0,3,6,9,12,15,18,21,24$, and 27 , both at morning and evening milkings. With the same frequency, milk samples were collected from each animal and stored at $4^{\circ} \mathrm{C}$ with a preservative (natamycin) until analyzed for fat, CP, lactose, and TS content. Milk FA composition was determined in unpreserved samples from each experimental lot that were collected on d $0,3,6,12,18$, and 27, composited according to individual milk yield, and stored at $-30^{\circ} \mathrm{C}$ until analysis.

Rumen Fluid. On d 29 of the experiment, ewes were milked and given free access to morning rations for $1 \mathrm{~h}$. Thereafter, feeds were removed and $3 \mathrm{~h}$ later, samples of rumen fluid were collected from each ewe using a stomach tube. Immediately after collection, the fluid was strained through 2 layers of muslin cloth, the $\mathrm{pH}$ was measured, and $4 \mathrm{~mL}$ was acidified with $4 \mathrm{~mL}$ of $0.2 \mathrm{M} \mathrm{HCl}$ for ammonia concentration determination.

Table 1. Ingredients and chemical composition of the experimental $\operatorname{diets}^{1}$

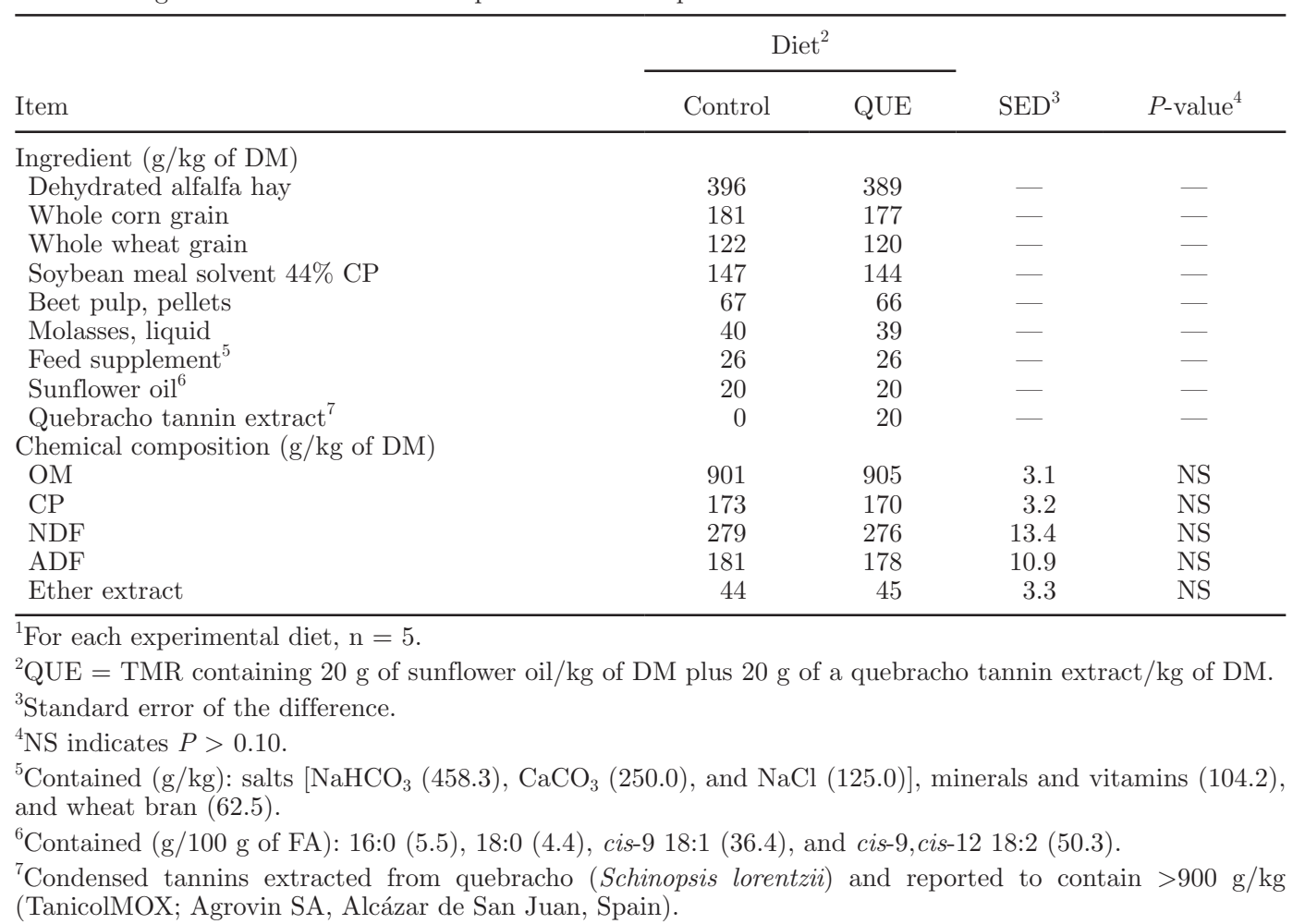


Further aliquots of 4 and $0.8 \mathrm{~mL}$ of ruminal fluid were taken for the analysis of lactic acid and VFA (deproteinized with $0.5 \mathrm{~mL}$ of $20 \mathrm{~g}$ of metaphosphoric acid/L and $4 \mathrm{~g}$ of crotonic acid/L in $0.5 \mathrm{M} \mathrm{HCl}$ ). All samples were stored at $-30^{\circ} \mathrm{C}$ until analysis.

\section{Chemical Analysis}

Diets. Diet samples were analyzed for DM (ISO, 1999a; ISO 6496:1999), ash (ISO, 2002; ISO 5984:2002), and CP (ISO, 2009; ISO 5983-2:2009) content. Neutral detergent fiber and ADF were determined by the methods described by Mertens (2002) and AOAC International (2006; method 973.18), respectively, using an Ankom ${ }^{2000}$ fiber analyzer (Ankom Technology Corp., Macedon, NY). Neutral detergent fiber was assayed with sodium sulfite and $\alpha$-amylase and expressed with residual ash (the latter also for ADF). The content of ether extract in the diets was determined by the Ankom filter bag technology (AOCS, 2008; procedure Am 5-04).

Milk. Fat, CP, lactose, and TS concentrations were determined by infrared spectrophotometry (ISO, 1999b; ISO 9622:1999), using a MilkoScan FT6000 (Foss Electric A/S, Hillerød, Denmark). For milk FA composition analysis, lipids in $1 \mathrm{~mL}$ of milk were extracted using diethyl ether and hexane $(5: 4, \mathrm{vol} / \mathrm{vol})$ and transesterified to FA methyl esters (FAME) using freshly prepared methanolic sodium methoxide, as outlined previously (Shingfield et al., 2003). Methyl esters were separated and quantified using a gas chromatograph (Agilent 7890A GC System; Agilent Technologies Inc., Santa Clara, CA) equipped with a flame-ionization detector and a $100-\mathrm{m}$ fused silica capillary column $(0.25-\mathrm{mm}$ i.d., 0.2- $\mu \mathrm{m}$ film thickness; CP-SIL 88, CP7489; Varian Ibérica SA, Madrid, Spain) and hydrogen as the carrier gas. The total FAME profile in a $2-\mu \mathrm{L}$ sample volume at a split ratio of 1:50 was determined using a temperature gradient program (Shingfield et al., 2003). Isomers of 18:1 were further resolved in a separate analysis under isothermal conditions at $170^{\circ} \mathrm{C}$ (Shingfield et al., 2003). Peaks were identified based on retention time comparisons with authentic standards (from Nu-Chek Prep., Elysian, MN; Sigma-Aldrich, Madrid, Spain; and Larodan Fine Chemicals AB, Malmö, Sweden), chromatograms reported in the literature (e.g., Shingfield et al., 2003; Kramer et al., 2008), and by comparison with milk samples for which the FA composition was determined based on gas chromatography analysis of FAME and GC-MS analysis of corresponding 4,4-dimethyloxazoline derivates.

Rumen Fluid. Ammonia and lactic acid concentrations were determined by colorimetric methods and
VFA by gas chromatography, using crotonic acid as an internal standard, as reported in Toral et al. (2011).

\section{Statistical Analysis}

All analyses were performed using the SAS software package (version 9.2; SAS Institute Inc., Cary, NC). Data on DMI, milk yield and composition, as well as FA composition, were analyzed for repeated measures using PROC MIXED and assuming a covariance structure fitted on the basis of Schwarz's Bayesian information model fit criterion. The statistical model included the fixed effects of diet, time, and their interaction and the initial record measured at 0 wk (covariate). Oneway ANOVA, using the PROC MIXED of SAS, was applied to data on rumen fermentation $(\mathrm{pH}$, and ammonia, lactate, and VFA concentrations). In all cases, the lot was nested within the diet and used as the error term to contrast the effect of quebracho supplementation. Differences were declared significant at $P<0.05$ and considered as tendencies toward significance at $P$ $<0.10$. Least squares means (adjusted for the covariance) are reported.

\section{RESULTS}

Inclusion of quebracho tannins in the diet supplemented with sunflower oil had no effect $(P>0.10)$ on any of the animal performance measurements monitored in this study. However, with the exception of DMI, all others (milk yield, and fat, protein, lactose, and TS proportions and yields) varied significantly over time (see Table 2).

Feeding the QUE diet caused only minor changes in ruminal fermentation characteristics. No differences $(P$ $>0.10)$ were observed between ewes fed the control (first value of the following pairs) or the QUE (last value) diet for $\mathrm{pH}$ (6.77 vs. 6.76$)$, or lactate (0.89 vs. $0.82 \mathrm{mmol} / \mathrm{L}$ ) and total VFA (110.1 vs. $107.8 \mathrm{mmol} / \mathrm{L})$ concentrations, or molar proportions of acetate, propionate, and butyrate (61.3 vs. $61.4,19.9$ vs. 20.3 , and 15.7 vs. $15.8 \mathrm{~mol} / 100 \mathrm{~mol}$, respectively). Although the concentration of ammonia was numerically higher in control ewes (160.4 vs. $135.4 \mathrm{mg} / \mathrm{L})$, it did not attain statistical significance. Only the molar proportion of minor VFA that mostly originated from deamination of some amino acids (namely, the sum of isobutyrate, isovalerate, valerate, and caproate) was reduced due to the addition of quebracho tannins (3.0 vs. $2.6 \mathrm{~mol} / 100$ mol; $P<0.05)$.

As reported in Tables 3 and 4 , the inclusion of quebracho extract was not effective $(P>0.10)$ in modifying the concentration of major classes of milk FA according 
Table 2. Dry matter intake, and milk yield and composition in ewes fed a TMR containing $20 \mathrm{~g}$ of sunflower oil $/ \mathrm{kg}$ of DM plus 0 (control diet) or $20 \mathrm{~g}$ of a quebracho tannin extract $/ \mathrm{kg}$ of DM (QUE diet)

\begin{tabular}{|c|c|c|c|c|c|c|}
\hline \multirow[b]{2}{*}{ Item } & \multicolumn{2}{|c|}{ Diet } & \multirow[b]{2}{*}{$\mathrm{SED}^{1}$} & \multicolumn{3}{|c|}{$P$-value ${ }^{2}$} \\
\hline & Control & QUE & & $\mathrm{D}$ & $\mathrm{T}$ & $\mathrm{D} \times \mathrm{T}$ \\
\hline DMI (g/d) & 2,956 & 2,949 & 193.6 & NS & NS & NS \\
\hline \multicolumn{7}{|l|}{ Yield (g/d) } \\
\hline Milk & 2,242 & 2,278 & 47.4 & NS & $* * *$ & NS \\
\hline Fat & 122.8 & 124.3 & 3.48 & NS & $* * *$ & NS \\
\hline $\mathrm{CP}$ & 111.4 & 112.1 & 2.28 & NS & $* * *$ & NS \\
\hline Lactose & 115.7 & 117.8 & 2.64 & NS & $* * *$ & NS \\
\hline TS & 369.7 & 374.9 & 5.25 & NS & $* * *$ & NS \\
\hline \multicolumn{7}{|c|}{ Composition ( $\mathrm{g} / 100 \mathrm{~g})$} \\
\hline Fat & 5.55 & 5.53 & 0.254 & NS & $* * *$ & NS \\
\hline $\mathrm{CP}$ & 4.97 & 4.94 & 0.047 & NS & $* * *$ & NS \\
\hline Lactose & 5.14 & 5.16 & 0.011 & NS & $* * *$ & NS \\
\hline $\mathrm{TS}$ & 16.55 & 16.54 & 0.289 & NS & $* * *$ & NS \\
\hline
\end{tabular}

${ }^{1}$ Standard error of the difference for diet (D) effects.

${ }^{2}$ Probability of significant effects due to experimental $\mathrm{D}$, time on $\mathrm{D}(\mathrm{T})$, and interaction $(\mathrm{D} \times \mathrm{T})$. NS indicates $P>0.10$.

*** $P<0.001$.

to the degree of saturation [with average $( \pm \mathrm{SE})$ contents of $65.4 \pm 0.22,27.3 \pm 0.16$, and $7.3 \pm 0.08 \mathrm{~g} / 100$ $\mathrm{g}$ of FA for SFA, MUFA, and PUFA, respectively]. However, the mean content of branched-chain FA was reduced with the QUE diet (1.80 vs. $1.67 \mathrm{~g} / 100 \mathrm{~g}$ of FA; $P<0.05)$, whereas that of odd-chain FA remained unchanged $(P>0.10)$.

On the contrary, tannin supplementation altered the proportions of major classes of milk FA according to their origin $(P<0.05)$. Thus, a greater concentration of FA originated from mammary uptake of plasma lipids (i.e., with $>16$ carbons) in ewes fed the QUE diet in comparison with the control diet (average contents of 45.0 vs. $43.1 \mathrm{~g} / 100 \mathrm{~g}$ of FA), which derived from increases in several 18:1 and 18:2 isomers and in most very long-chain n-6 PUFA (Table 4). Some of these changes were relatively constant throughout the experiment (e.g., cis-12 18:1, trans-9,cis-11 CLA, and trans9,cis-12 18:2), whereas others were only evident after a long time on the QUE diet (e.g., trans-5, trans-10, and trans-13 and -14 18:1). In contrast, differences between treatments in trans-11 18:1 were only observed on d 3 of the experiment (Figure 1). The significant interaction for milk 18:0 concentration was limited to a transient decrease on $\mathrm{d} 6$ in ewes fed the control diet.

In agreement with the increase in preformed $\mathrm{FA}$, the addition of QUE slightly reduced $(P<0.05)$ the relative proportions of FA synthesized de novo in the mammary gland (i.e., with $<16$ carbons; $-3.9 \%$ ) or derived in equal amounts from both sources (i.e., with 16 carbons; $-4.3 \%$ ). Consistent reductions were also observed for most particular FA with 16 or fewer carbons affected by tannin supplementation (e.g., 10:0, cis-9 and trans-9 12:1, cis-12 14:1, 16:0, and cis-14 16:1).

\section{DISCUSSION}

The controversy in the literature surrounding the ability of tannins to modulate the FA profile of ruminantderived products (Vasta and Luciano, 2011) is probably due to the great diversity in the structural features and, consequently, in the reactivity of these secondary compounds (Mueller-Harvey, 2006). Although attempts to attribute different nutritional effects to generic tannin classes have not proven useful (Mueller-Harvey, 2006), widespread perception exists that condensed tannins are less toxic and more efficient than hydrolysable ones, probably based on the ability of rumen microorganisms to degrade hydrolysable tannins (McSweeney et al., 2001; Makkar, 2003).

The dose-dependent effect of tannins is another major issue because of the difficulty in selecting concentrations to positively affect a particular parameter without conferring a negative response in others (e.g., in overall diet utilization; Makkar, 2003). The amount of quebracho tannin extract used in this experiment was chosen with 2 criteria: the ability to modulate ruminal $\mathrm{BH}$ of linoleic acid without impairing animal performance, and the practicality under farm conditions. Some in vitro studies (Khiaosa-Ard et al., 2009; Vasta et al., 2009a; Buccioni et al., 2011) have found a desirable effect of tannins on ruminal BH at very high doses (up to $18 \%$ of the DM incubated). However, such high levels would be impractical in terms of animal feeding.

In the present experiment, inclusion of $20 \mathrm{~g}$ of quebracho tannin extract $/ \mathrm{kg}$ of diet DM had no apparent detrimental effects on animal performance, which is consistent with studies using low to moderate doses of condensed tannin extracts in ruminants (Benchaar et 
Table 3. Saturated FA composition of milk from ewes fed a TMR containing $20 \mathrm{~g}$ of sunflower oil/ $\mathrm{kg}$ of DM plus 0 (control diet) or $20 \mathrm{~g}$ of a quebracho tannin extract/kg of DM (QUE diet)

\begin{tabular}{|c|c|c|c|c|c|c|}
\hline FA $(g / 100 \mathrm{~g}$ of $\mathrm{FA})$ & \multicolumn{2}{|c|}{ Diet } & $\mathrm{SED}^{1}$ & \multicolumn{3}{|c|}{$P$-value ${ }^{2}$} \\
\hline 5:0 & 0.019 & 0.016 & 0.0017 & NS & $*$ & $\dagger$ \\
\hline $6: 0$ & 2.596 & 2.608 & 0.0641 & NS & $* * *$ & NS \\
\hline $7: 0$ & 0.038 & 0.033 & 0.0025 & NS & $\dagger$ & NS \\
\hline $8: 0$ & 2.860 & 2.893 & 0.1020 & NS & $* *$ & NS \\
\hline 11:0 & 0.091 & 0.091 & 0.0112 & NS & NS & NS \\
\hline $12: 0$ & 4.941 & 4.651 & 0.1108 & $\dagger$ & NS & NS \\
\hline iso $13: 0$ & 0.013 & 0.012 & 0.0013 & NS & NS & NS \\
\hline anteiso 13:0 & 0.008 & 0.008 & 0.0003 & NS & $* *$ & NS \\
\hline 4,8,12-trimethyl 13:0 & 0.075 & 0.067 & 0.0104 & NS & $*$ & NS \\
\hline $14: 0$ & 9.893 & 9.634 & 0.1707 & NS & $*$ & NS \\
\hline iso 14:0 & 0.084 & 0.090 & 0.0039 & NS & $* *$ & NS \\
\hline 3,7,11,15-tetramethyl 16:0 & 0.023 & 0.023 & 0.0011 & NS & $\dagger$ & NS \\
\hline $17: 0$ & 0.486 & 0.505 & 0.0063 & $*$ & $\dagger$ & NS \\
\hline iso $17: 0$ & 0.294 & 0.288 & 0.0090 & NS & $*$ & NS \\
\hline anteiso 17:0 & 0.418 & 0.398 & 0.0080 & $*$ & $* *$ & NS \\
\hline 18:0 & 9.108 & 9.419 & 0.3400 & NS & $* *$ & $*$ \\
\hline iso $18: 0$ & 0.054 & 0.056 & 0.0024 & NS & $\dagger$ & NS \\
\hline 10-охо-18:0 & 0.022 & 0.025 & 0.0052 & NS & NS & NS \\
\hline 13-oxo-18:0 & 0.006 & 0.006 & 0.0009 & NS & NS & NS \\
\hline 19:0 & 0.090 & 0.092 & 0.0031 & NS & NS & NS \\
\hline $20: 0$ & 0.186 & 0.195 & 0.0027 & $*$ & $* *$ & NS \\
\hline 21:0 & 0.057 & 0.056 & 0.0015 & NS & NS & NS \\
\hline $22: 0$ & 0.127 & 0.131 & 0.0029 & NS & $*$ & $*$ \\
\hline $23: 0$ & 0.054 & 0.053 & 0.0027 & NS & * & $\dagger$ \\
\hline $24: 0$ & 0.036 & 0.036 & 0.0040 & NS & $* *$ & NS \\
\hline
\end{tabular}

${ }^{1}$ Standard error of the difference for diet (D) effects.

${ }^{2}$ Probability of significant effects due to experimental $\mathrm{D}$, time on $\mathrm{D}(\mathrm{T})$, and their interaction $(\mathrm{D} \times \mathrm{T})$. NS indicates $P>0.10$.

$\dagger P<0.10 ;{ }^{*} P<0.05 ;{ }^{*} P<0.01 ;{ }^{*} * * P<0.001$.

al., 2008; Toral et al., 2011), and may be related to the lack of negative effects on ruminal fermentation. On the other hand, diet supplementation with quebracho was not able to beneficially modify milk FA composition, especially in the long term. Results on long-chain FA concentration in milk fat suggest that, in contrast with some studies in dairy cows (Benchaar and Chouinard, 2009) and ewes (Toral et al., 2011), the higher amount of quebracho extract used in this trial $(2 \% \mathrm{DM})$ would have affected ruminal $\mathrm{BH}$. Unfortunately, the goal of promoting the accumulation of trans-11 18:1 in the rumen to enhance milk CLA concentration would have been achieved only transiently, as pairwise comparisons between treatments for each sampling day indicate that the QUE diet only increased the relative milk content of trans-11 18:1 and its $\Delta^{9}$-desaturation product, cis9,trans-11 CLA, on d 3 of the experiment (Figure 1). These time-dependent changes might be attributed to the effect of condensed tannins inhibiting the last step of ruminal BH (i.e., the conversion of trans-11 18:1 to 18:0), as shown in in vitro assays (Khiaosa-Ard et al., 2009; Vasta et al., 2009a), as well as to a potential adaptation of rumen microbiota to the presence of tannins in the diet (McSweeney et al., 2001).

Results for milk FA composition were also compatible with changes in the putative pathways of ruminal BH of cis-9,cis-12 18:2, the most abundant FA in the sunflower oil included in the basal diet. On the one hand, feeding the QUE diet induced stable increases in milk fat concentration of trans-9,cis-12 18:2 and cis-12 18:1. These metabolites would derive from a minor $\mathrm{BH}$ pathway in which the cis-9 double bond of cis-9,cis-12 18:2 is initially isomerized and subsequently reduced in the rumen (Shingfield et al., 2010). The increase in cis-12 18:1 may also be accounted for by the direct reduction of the cis-9 double bond of cis-9,cis-12 18:2 or the hydrogenation of some 18:2 intermediates, such as trans-10,cis-12 or cis-10,cis-12 CLA (McKain et al., 
Table 4. Unsaturated FA composition of milk from ewes fed a TMR containing $20 \mathrm{~g}$ of sunflower oil/ $\mathrm{kg}$ of DM plus 0 (control diet) or $20 \mathrm{~g}$ of a quebracho tannin extract/kg of DM (QUE diet)

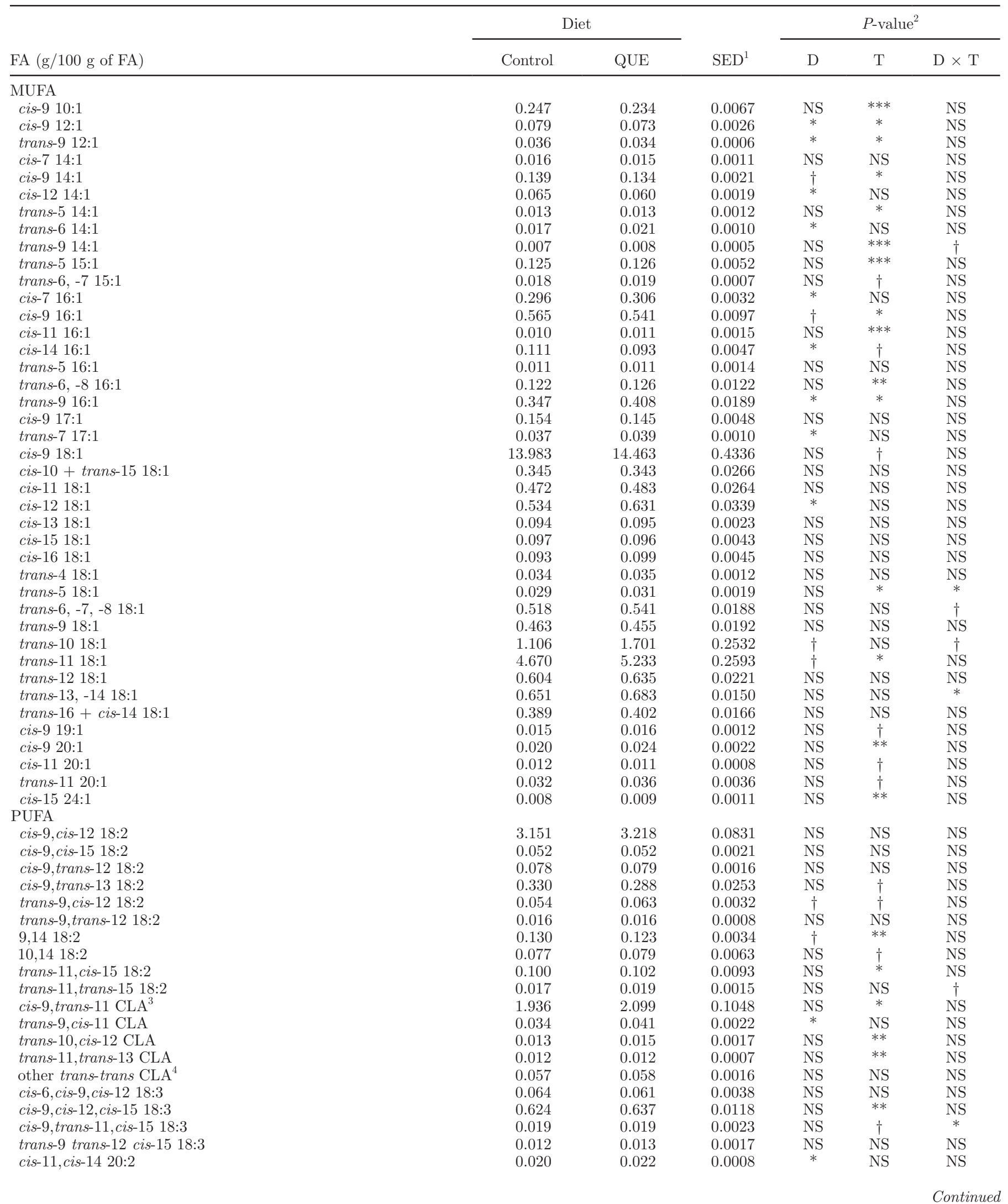


Table 4 (Continued). Unsaturated FA composition of milk from ewes fed a TMR containing $20 \mathrm{~g}$ of sunflower oil/ $\mathrm{kg}$ of DM plus 0 (control diet) or $20 \mathrm{~g}$ of a quebracho tannin extract/kg of DM (QUE diet)

\begin{tabular}{|c|c|c|c|c|c|c|}
\hline FA $(g / 100 \mathrm{~g}$ of FA) & \multicolumn{2}{|c|}{ Diet } & $\mathrm{SED}^{1}$ & \multicolumn{3}{|c|}{$P$-value ${ }^{2}$} \\
\hline cis-8,cis-11,cis-14 20:3 & 0.032 & 0.037 & 0.0023 & $\dagger$ & $* *$ & NS \\
\hline cis-5,cis-8,cis-11,cis-14 20:4 & 0.159 & 0.173 & 0.0048 & $*$ & NS & NS \\
\hline cis-5,cis-8,cis-11,cis-14,cis-17 20:5 & 0.045 & 0.045 & 0.0021 & NS & $* * *$ & NS \\
\hline cis-7,cis-10,cis-13,cis-16 22:4 & 0.021 & 0.024 & 0.0008 & $*$ & $* *$ & NS \\
\hline
\end{tabular}

${ }^{1}$ Standard error of the difference for diet (D) effects.

${ }^{2}$ Probability of significant effects due to experimental D, time on $\mathrm{D}(\mathrm{T})$, and their interaction $(\mathrm{D} \times \mathrm{T})$. NS indicates $P>0.10$.

${ }^{3}$ Contains trans-7, cis-9 conjugated linoleic acid (CLA) and trans-8, cis-10 CLA as minor components.

${ }^{4}$ Sum of trans-7,trans-9 CLA + trans-8,trans-10 CLA + trans-9,trans-11 CLA + trans-10,trans-12 CLA.

$\dagger P<0.10 ;{ }^{*} P<0.05 ;{ }^{* *} P<0.01 ; * * * P<0.001$

2010; Honkanen et al., 2012). In all cases, these results suggest changes in the rumen bacterial community of QUE-fed ewes favoring populations able to metabolize cis-9, cis-12 18:2 via mechanisms other than isomerization of the cis-12 double bond (McKain et al., 2010; Honkanen et al., 2012).

On the other hand, feeding the QUE diet induced time-dependent increases in other $\mathrm{BH}$ intermediates, such as trans 18:1 isomers that were particularly evident in the trans-10 18:1 (Figure 1) and indicate shifts in rumen bacterial populations and, consequently, in $\mathrm{BH}$ pathways due to the long-term consumption of tannins (McSweeney et al., 2001). Previous studies in lactating sheep fed condensed tannins have shown inconsistent results for trans-10 18:1 variations in milk fat, with no differences (Toral et al., 2011), increases (Abbeddou et al., 2011), or even slight decreases (Cabiddu et al., 2009), which could be attributed not only to the type and dose of tannins but also to the basal diet composition (Vasta et al., 2009b). Accumulation in milk of this trans FA has also been reported in ewes and cows fed marine lipids (Chilliard et al., 2007; Toral et al., 2010). However, the marked shift toward trans-10 18:1 formation at the expense of trans-11 18:1 in response to marine lipids is often accompanied by milk fat depression (Shingfield et al., 2010; Toral et al., 2010), whereas dietary quebracho tannins resulted in trans-11 18:1 concentrations always being much higher than those of trans-10 18:1 (Figure 1) and no effects on milk fat content. The health-related value of the increase in trans-10 18:1 in milk from ewes fed the QUE diet is not clear because of the uncertain involvement of this trans FA in cardiovascular disease (Gebauer et al., 2011).

The increase in trans-9,cis-11 CLA might also be of relevance due to its potential antilipogenic effect in the mammary gland (Perfield et al., 2007; Shingfield et al.,
2010), but, given its low concentration, no reduction in milk fat content was observed in this experiment. Although some studies have reported concomitant increases in trans-9,cis-11 CLA and trans-10 18:1 milk concentrations (Shingfield et al., 2010; Toral et al., 2010), no apparent association between both trans FA profiles was observed in the present study. All these changes in milk FA composition might be attributed to an effect of quebracho tannins on rumen microbiota, as supported by the variations in milk branched-chain FA, which are largely derived from bacteria leaving the rumen (Fievez et al., 2012).

Surprisingly, feeding the QUE diet also affected the concentration of most very long-chain n-6 PUFA. However, the fact that these FA are usually detected in very low concentrations in rumen digesta (Shingfield et al., 2003; Toral et al., 2012) would probably rule out a direct effect of tannins on their rumen outflow as the principal factor responsible for the increase. Under normal feeding conditions, PUFA with 20 and 22 carbons in milk fat would mostly derive from mammary uptake of FA synthesized and recirculated by other body tissues. In the particular case of very long-chain n-6 PUFA, whose hepatic synthesis involves alternating steps of elongation and desaturation of cis-9, cis-12 18:2 from dietary origin (Miyazaki and Ntambi, 2008), their increase might be mediated by a systemic action of QUE supplementation attributable to the low molecular weight phenolics included in the commercial extract. These compounds would be absorbed from the digestive tract (Makkar, 2003) and affect lipid metabolism in the liver or other body tissues. Finally, the slight reduction in the relative proportions of FA partially or totally synthesized de novo in the mammary gland (i.e., with 16 or less carbons) with the QUE diet may be explained by a dilution effect or by the changes 

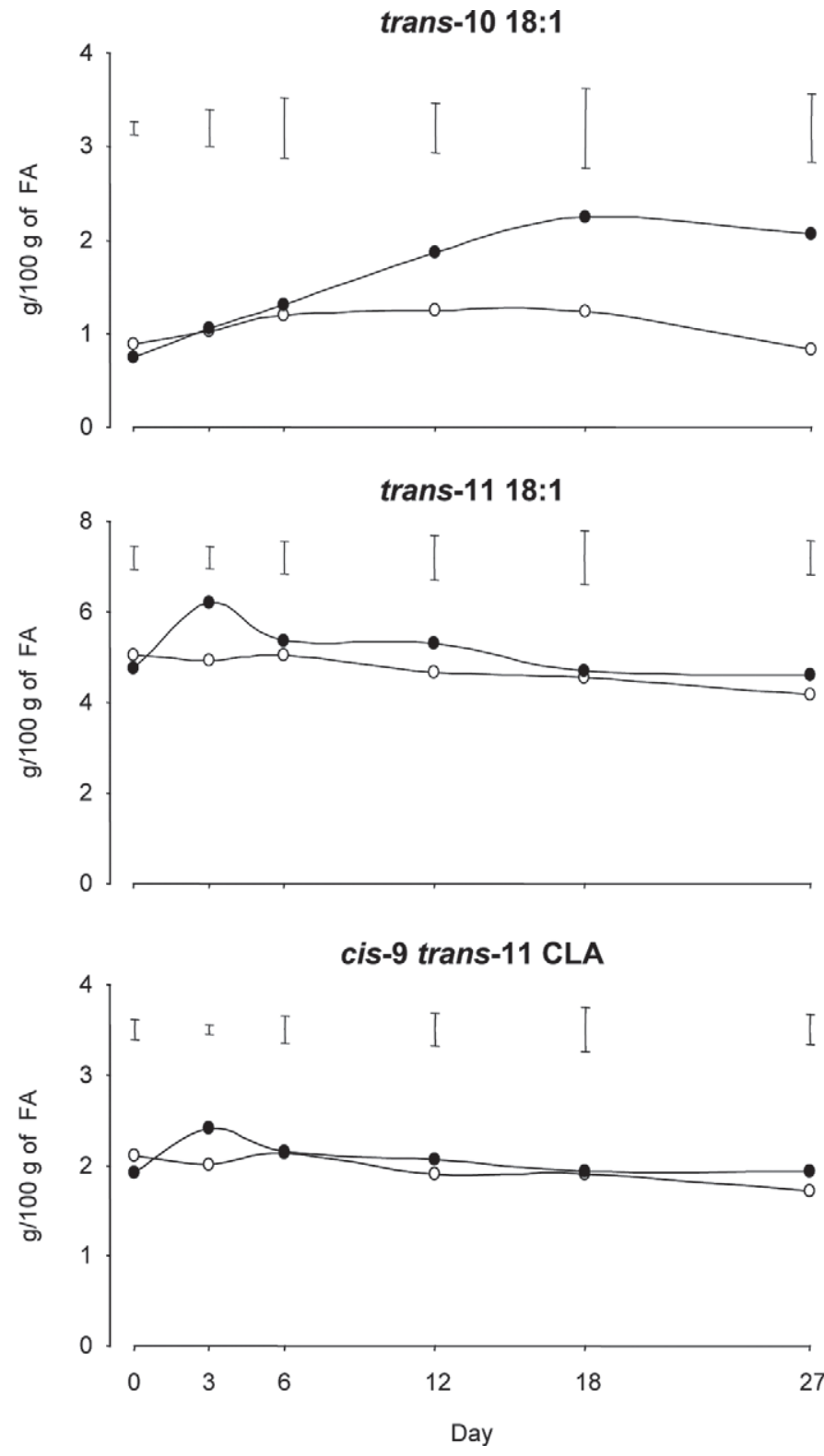

Figure 1. Temporal changes in milk trans-10 18:1, trans-11 18:1, and cis-9,trans-11 conjugated linoleic acid (CLA; g/100 g of FA) in ewes fed a TMR containing $20 \mathrm{~g}$ of sunflower oil $/ \mathrm{kg}$ of DM plus 0 (control diet; $\bigcirc$ ) or $20 \mathrm{~g}$ of a quebracho tannin extract $/ \mathrm{kg}$ of DM (QUE diet; $)$. Values are the mean from 3 lots of 6 animals per lot; vertical bars represent the standard error of the difference.

in preformed FA, given the inhibitory effect of these metabolites (especially trans FA) on mammary de novo synthesis (Shingfield et al., 2010).

\section{CONCLUSIONS}

Overall, addition of QUE to a diet rich in linoleic acid did not prove useful to modulate milk FA composition, especially in the long term. Quebracho tannins are profisetinidins with more compact, less accessible structures than other condensed tannins and, although they can exert beneficial effects in ruminants (MuellerHarvey, 2006), they do not seem to strongly affect rumen microorganisms involved in $\mathrm{BH}$. Therefore, further research is needed to investigate if other tannins, at practical doses, are more efficient at modulating ruminal biohydrogenation of dietary PUFA.

\section{ACKNOWLEDGMENTS}

This work was supported by the Spanish Ministry of Economy and Competitiveness (MINECO, Madrid, Spain; AGL2011-23700). E. Bichi gratefully acknowledges receipt of a predoctoral grant from the Spanish National Research Council [CSIC, Madrid, Spain; Junta de Ampliación de Estudios (JAE) Programme] supported by the European Social Fund. The authors thank the research farm staff for their help in the fieldwork and S. L. Kronberg [US Department of Agriculture-Agricultural Research Service (USDA-ARS), Mandan, ND] for helpful revision of the manuscript.

\section{REFERENCES}

Abbeddou, S., B. Rischkowsky, E. K. Richter, H. D. Hess, and M. Kreuzer. 2011. Modification of milk fatty acid composition by feeding forages and agro-industrial byproducts from dry areas to Awassi sheep. J. Dairy Sci. 94:4657-4668.

AOAC International. 2006. Official Methods of Analysis of AOAC International. 18th ed. 1st rev. AOAC International, Gaithersburg, MD.

AOCS (American Oil Chemists' Society). 2008. Official Methods and Recommended Practices of the American Oil Chemist's Society. 5th ed. AOCS, Urbana, IL.

Benchaar, C., and P. Y. Chouinard. 2009. Assessment of the potential of cinnamaldehyde, condensed tannins, and saponins to modify milk fatty acid composition of dairy cows. J. Dairy Sci. 92:33923396.

Benchaar, C., T. A. McAllister, and P. Y. Chouinard. 2008. Digestion, ruminal fermentation, ciliate protozoal populations, and milk production from dairy cows fed cinnamaldehyde, quebracho condensed tannin, or Yucca schidigera saponin extracts. J. Dairy Sci. 91:4765-4777.

Buccioni, A., S. Minieri, S. Rapaccini, M. Antongiovanni, and M. Mele. 2011. Effect of chestnut and quebracho tannins on fatty acid profile in rumen liquid- and solid-associated bacteria: An in vitro study. Animal 5:1521-1530.

Cabiddu, A., G. Molle, M. Decandia, S. Spada, M. Fiori, G. Piredda, and M. Addis. 2009. Responses to condensed tannins of flowering sulla (Hedysarum coronarium L.) grazed by dairy sheep. Part 2: Effects on milk fatty acid profile. Livest. Sci. 123:230-240.

Chilliard, Y., F. Glasser, A. Ferlay, L. Bernard, J. Rouel, and M. Doreau. 2007. Diet, rumen biohydrogenation and nutritional quality of cow and goat milk fat. Eur. J. Lipid Sci. Technol. 109:828855.

Fievez, V., E. Colman, J. M. Castro-Montoya, I. Stefanov, and B Vlaeminck. 2012. Milk odd- and branched-chain fatty acids as biomarkers of rumen function-An update. Anim. Feed Sci. Technol. $172: 51-65$

Gebauer, S. K., J. M. Chardigny, M. U. Jakobsen, B. Lamarche, A. L. Lock, S. D. Proctor, and D. J. Baer. 2011. Effects of ruminant trans fatty acids on cardiovascular disease and cancer: A compre- 
hensive review of epidemiological, clinical, and mechanistic studies. Adv. Nutr. 2:332-354.

Hervás, G., P. Luna, A. R. Mantecón, N. Castañares, M. A. de la Fuente, M. Juárez, and P. Frutos. 2008. Effect of diet supplementation with sunflower oil in milk production, fatty acid profile and ruminal fermentation in lactating ewes. J. Dairy Res. 75:399-405.

Honkanen, A. M., J. M. Griinari, A. Vanhatalo, S. Ahvenjärvi, V. Toivonen, and K. J. Shingfield. 2012. Characterization of the disappearance and formation of biohydrogenation intermediates during incubations of linoleic acid with rumen fluid in vitro. J. Dairy Sci. 95:1376-1394.

ISO (International Organization for Standardization). 1999a. Animal feeding stuffs - Determination of moisture and other volatile matter content. ISO 6496:1999 (ISO, Geneva, Switzerland.).

ISO (International Organization for Standardization). 1999b. Whole milk-Determination of milkfat, protein and lactose contentGuidance on the operation of mid-infrared instruments. ISO 9622:1999 (ISO, Geneva, Switzerland.).

ISO (International Organization for Standardization). 2002. Animal feeding stuffs - Determination of crude ash. ISO 5984:2002. ISO, Geneva, Switzerland.

ISO (International Organization for Standardization). 2009. Animal feeding stuffs - Determination of nitrogen content and calculation of crude protein content-Part 2: Block digestion and steam distillation method. ISO 5983-2:2009. ISO, Geneva, Switzerland.

Khiaosa-Ard, R., S. F. Bryner, M. R. L. Scheeder, H. R. Wettstein, F. Leiber, M. Kreuzer, and C. R. Soliva. 2009. Evidence for the inhibition of the terminal step of ruminal $\alpha$-linolenic acid biohydrogenation by condensed tannins. J. Dairy Sci. 92:177-188.

Khiaosa-ard, R., C. R. Soliva, M. Kreuzer, and F. Leiber. 2011. Influence of alpine forage either employed as donor cow's feed or as incubation substrate on in vitro ruminal fatty acid biohydrogenation. Livest. Sci. 140:80-87.

Kramer, J. K. G., M. Hernandez, C. Cruz-Hernandez, J. Kraft, and M. E. R. Dugan. 2008. Combining results of two GC separations partly achieves determination of all cis and trans 16:1, 18:1, 18:2 and 18:3 except CLA isomers of milk fat as demonstrated using Ag-ion SPE fractionation. Lipids 43:259-273.

Kronberg, S. L., E. J. Scholljegerdes, G. Barceló-Coblijn, and E. J. Murphy. 2007. Flaxseed treatments to reduce biohydrogenation of $\alpha$-linolenic acid by rumen microbes in cattle. Lipids 42:1105-1111.

Lock, A. L., and D. E. Bauman. 2004. Modifying milk fat composition of dairy cows to enhance fatty acids beneficial to human health. Lipids 39:1197-1206.

Makkar, H. P. S. 2003. Effects and fate of tannins in ruminant animals, adaptation to tannins, and strategies to overcome detrimental effects of feeding tannin-rich feeds. Small Rumin. Res. 49:241-256.

McKain, N., K. J. Shingfield, and R. J. Wallace. 2010. Metabolism of conjugated linoleic acids and 18:1 fatty acids by ruminal bacteria: Products and mechanisms. Microbiology 156:579-588.
McSweeney, C. S., B. Palmer, D. M. McNeill, and D. O. Krause. 2001. Microbial interactions with tannins: Nutritional consequences for ruminants. Anim. Feed Sci. Technol. 91:83-93.

Mertens, D. R. 2002. Gravimetric determination of amylase-treated neutral detergent fiber in feeds with refluxing in beakers or crucibles: Collaborative study. J. AOAC Int. 85:1217-1240.

Miyazaki, M., and J. M. Ntambi. 2008. Fatty acid desaturation and chain elongation in mammals. Pages 191-211 in Biochemistry of Lipids, Lipoproteins and Membranes. 5th ed. D. E. Vance and J. E. Vance., ed. Elsevier BV, Oxford, UK.

Mueller-Harvey, I. 2006. Unravelling the conundrum of tannins in animal nutrition and health. J. Sci. Food Agric. 86:2010-2037.

Perfield, J. W., A. L. Lock, J. M. Griinari, A. Sæbø, P. Delmonte, D. A. Dwyer, and D. E. Bauman. 2007. Trans-9, cis-11 conjugated linoleic acid reduces milk fat synthesis in lactating dairy cows. J. Dairy Sci. 90:2211-2218.

Shingfield, K. J., S. Ahvenjärvi, V. Toivonen, A. Ärölä, K. V. V. Nurmela, P. Huhtanen, and J. M. Griinari. 2003. Effect of dietary fish oil on biohydrogenation of fatty acids and milk fatty acid content in cows. Anim. Sci. 77:165-179.

Shingfield, K. J., L. Bernard, C. Leroux, and Y. Chilliard. 2010. Role of trans fatty acids in the nutritional regulation of mammary lipogenesis in ruminants. Animal 4:1140-1166.

Toral, P., G. Hervás, E. Bichi, A. Belenguer, and P. Frutos. 2011. Tannins as feed additives to modulate ruminal biohydrogenation: Effects on animal performance, milk fatty acid composition and ruminal fermentation in dairy ewes fed a diet containing sunflower oil. Anim. Feed Sci. Technol. 164:199-206.

Toral, P. G., A. Belenguer, K. J. Shingfield, G. Hervás, V. Toivonen, and P. Frutos. 2012. Fatty acid composition and bacterial community changes in the rumen fluid of lactating sheep fed sunflower oil plus incremental levels of marine algae. J. Dairy Sci. 95:794-806.

Toral, P. G., G. Hervás, P. Gómez-Cortés, P. Frutos, M. Juárez, and M. A. de la Fuente. 2010. Milk fatty acid profile and dairy sheep performance in response to diet supplementation with sunflower oil plus incremental levels of marine algae. J. Dairy Sci. 93:16551667.

Vasta, V., and G. Luciano. 2011. The effects of dietary consumption of plants secondary compounds on small ruminants' products quality. Small Rumin. Res. 101:150-159.

Vasta, V., H. P. S. Makkar, M. Mele, and A. Priolo. 2009a. Ruminal biohydrogenation as affected by tannins in vitro. Br. J. Nutr. 102:82-92.

Vasta, V., M. Mele, A. Serra, M. Scerra, G. Luciano, M. Lanza, and A. Priolo. 2009b. Metabolic fate of fatty acids involved in ruminal biohydrogenation in sheep fed concentrate or herbage with or without tannins. J. Anim. Sci. 87:2674-2684. 